\title{
DISERTACIONES
}

ENSAYOS

\section{LA PANDEMIA DE LA COVID-19 COMO DEBATE PÚBLICO: EL CASO ESPAÑOL}

\section{The covID-19 Pandemic as an Open Debate: The Spanish Case}

\section{A pandemia coviD-19 como um debate público: o caso espanhol}

Miguel Alcíbar, Universidad de Sevilla (España)

jalcibar@us.es

Recibido: 2 de marzo de 2021

Aprobado: 30 de marzo de 2021

Fecha de prepublicación: 21 de junio de 2021

\section{RESUMEN}

El objetivo de este artículo es examinar las líneas básicas de la gestión política de la crisis sanitaria provocada por la pandemia de la covid-19 (acrónimo del inglés coronavirus disease 2019) en España. En este sentido, se exploran algunos debates públicos que implican aspectos científicos, políticos, económicos y sociales de esta controversia sociocientífica. Aunque el grueso de las reflexiones se ciñe al caso español (en concreto, los debates sobre economía frente a salud, y sobre confianza y credibilidad en las instituciones), también se aborda el debate sobre el origen del coronavirus, de alcance internacional. Con una metodología cualitativa se analiza el discurso de una muestra intencional de mensajes públicos. Se concluye que hay que extraer tres lecciones: respuesta global, centralización de las competencias o mejor coordinación en el territorio español y un plan de comunicación riguroso, coordinado, serio y transparente. Respecto de la gestión de la covid-19 se apunta a los estudios comparativos con el objeto de dilucidar los factores estructurales y coyunturales.

Palabras clave: covID-19; SARS-CoV-2; pandemia; comunicación política; controversia sociocientífica. 


\section{ABSTRACT}

This paper analyzes the basic lines of the political management of health crisis caused by the covid-19 pandemic (acronym of the coronavirus disease 2019) in Spain. In this regard, several public debates involving scientific, political, economic, and social aspects of this socio-scientific controversy were explored. Although most viewpoints focus on the Spanish case (specifically the debates on the economy in terms of health, as well as trust and credibility in institutions), it also addresses the debate on the origin of coronavirus, international in scope. Using a qualitative methodology, it is analyzed the discourse of an intentional sample of public messages. It is concluded that three lessons must be drawn: global response, centralization of competencies or better coordination in Spanish territory, and a rigorous, coordinated, serious and transparent communication plan. Regarding the management of coviD-19 comparative studies are pointed out with the goal of elucidating structural and conjunctural factors.

Keywords: covID-19; SARS-CoV-2; pandemic; political communication; socio-scientific controversy.

\section{RESUMO}

O objetivo deste ensaio é examinar as linhas básicas de gestão política da crise de saúde causada pela pandemia covid-19 (sigla em inglês para coronavirus disease 2019) na Espanha. Nesse sentido, exploro alguns debates públicos que envolvem aspectos científicos, políticos, econômicos e sociais dessa polêmica sociocientífica. Embora o grosso das reflexões se restrinja ao caso espanhol (especificamente, os debates sobre economia versus saúde, e sobre confiança e credibilidade nas instituições), o debate sobre a origem do coronavírus, de âmbito internacional, também é abordado. Com uma metodologia qualitativa, analisa-se o discurso de uma amostra intencional de mensagens públicas. Conclui-se que devem ser tiradas três lições: resposta global, centralização de competências ou melhor coordenação no território espanhol, e um plano de comunicação rigoroso, coordenado, sério e transparente. Em relação ao manejo do covid-19, apontam-se estudos comparativos a fim de elucidar os fatores estruturais e conjunturais.

Palavras-chave: covID-19; SARS-CoV-2; pandemia; comunicação política; controvérsia sociocientífica. 


\section{DISERTACIONES}

ENSAYOS

\section{Introducción}

El 31 de diciembre de 2019, las autoridades chinas informan a la Organización Mundial de la Salud (oms) que habían detectado 27 casos de neumonía de etiología desconocida en un mercado mojado de la ciudad de Wuhan, provincia de Hubei. El patógeno emergente responsable de esta neumonía atípica, denominado SARS-CoV-2 (del inglés Severe Acute Respiratory Syndrome Coronavirus 2), pertenece a la familia de los coronavirus, cuyos representantes más conocidos son SARS-CoV y MERS-CoV. Aunque el origen del virus es incierto, la hipótesis más plausible es que se trate de una zoonosis, es decir, de un proceso por el cual un patógeno salta de una especie animal (presumiblemente, un mamífero) al ser humano y le provoca una enfermedad infecciosa. La enfermedad asociada al SARS-CoV-2 ha recibido el nombre de covid-19.

La pandemia de la covid-19 es un producto de la globalización, de la interconexión entre todos los lugares del planeta. Desde China, el coronavirus se propaga rápidamente a otros países asiáticos, como Tailandia y Corea del Sur, para, algo más tarde, llegar a Europa y al resto del mundo. A pesar de tratarse de un problema global, la respuesta ha sido principalmente nacional y, hasta el momento, la coordinación planetaria ha sido paupérrima. De hecho, el papel de la oms al comienzo de la crisis se deberá estudiar con atención, puesto que en todo momento sus recomendaciones parecen haber ido por detrás de lo que estaba sucediendo. La falta de respuesta a escala mundial hace que los Gobiernos de los distintos países implementen diferentes estrategias de comunicación para explicar las medidas que van adoptando para frenar la expansión del virus, de tal manera que en unos son más eficaces que en otros y, por consiguiente, los efectos perjudiciales son menores en los primeros que en los segundos. En mayor o menor medida, los Gobiernos nacionales han usado poderes excepcionales para lograr que se cumpla con los confinamientos, a menudo sacrificando las libertades civiles y alterando profundamente el equilibrio de poder preexistente, que alimenta los temores de un giro autoritario (Amat et al., 2020).

En este artículo, reflexiono sobre las controversias sociocientíficas y exploro algunos de los debates que involucran aspectos científicos, políticos, económicos y sociales, asociados con la pandemia de la covid-19, tomando como referente el contexto español.

\section{La pandemia en España}

En España, nos hemos acostumbrado a que de media mueran diariamente por la covid-19 tantas personas como pasajeros llenan dos aviones comerciales. Con una población aproximada de 47 millones, es uno de los países con más mortalidad del mundo, debida a la pandemia. Por ejemplo, al 25 de abril de 2020, con 482 decesos es el segundo país con más muertes por millón de habitantes confirmadas oficialmente (Worldometer, 2020), así como el que muestra una mayor tasa de profesionales sanitarios infectados: $20 \%$, frente al $10 \%$ de Italia y al $3 \%$ de Estados Unidos (European Centre for Disease Prevention and Control [ECDC], 2020a). Según la base de datos de la Universidad Johns Hopkins, a 31 de enero de 2021, España registra 124,82 muertes por cada 100000 habitantes, con lo que ocupa el decimoctavo puesto mundial, solo por detrás de países poblados como Reino Unido $(159,09)$, Italia $(146,08)$, Estados Unidos $(134,32)$, Perú $(127,72)$ y México $(125,27)$ (Coronavirus Resource Center, 2021). Por tanto, España es uno de los países más castigados por el SARS-CoV-2, a pesar de que los indicadores muestran que goza de uno de los sistemas de salud más vigorosos del mundo (World Economic Forum, 2019; Fullman et al., 2018). 


\section{DISERTACIONES}

ENSAYOS

Comunicación y controversias sociocientíficas en salud y medio ambiente

ISSN: $1856-9536$

Doi: https://doi.org/10.12804/revistas.urosario.edu.co/disertaciones/a.10334

Volumen 14, Número 2 / Julio-diciembre 2021

Versión PDF para imprimir desde

http://revistas.urosario.edu.co/index.php/disertaciones

En una carta publicada el 22 de agosto de 2020 en la prestigiosa revista médica The Lancet, varios expertos españoles en salud pública, epidemiología y virología, entre otras disciplinas biomédicas, exponen las causas que pueden explicar estos datos y solicitan del Gobierno de España que acepte una evaluación independiente e imparcial por parte de un panel de expertos internacionales y nacionales, centrada en las actividades del Gobierno central y de los Gobiernos de las comunidades autónomas (García-Basteiro et al., 2020). Entre las causas alegadas destacan la falta de preparación para afrontar una pandemia (sistemas de vigilancia débiles, baja capacidad para realizar pruebas PCR y escasez de equipos de protección personal y de cuidados intensivos), la reacción tardía de las autoridades gubernativas centrales y regionales, los altos niveles de movilidad poblacional, la mala coordinación entre el Gobierno central y los respectivos Gobiernos autonómicos, la escasa dependencia del asesoramiento científico, el envejecimiento de la población y la falta de preparación en las residencias de ancianos. ${ }^{1}$ Además, estos problemas se han visto agravados por una década de austeridad. En el mismo sentido se expresa The Lancet en su editorial del 16 de octubre de 2020, titulado “covid-19 in Spain: A Predictable Storm?", cuando ahonda en las deficiencias estructurales y en los errores de gestión que convierten a España en uno de los países más afectados en la segunda ola de la pandemia.

Un factor clave para entender la magnitud de la crisis es la organización territorial del Estado español, cuyas competencias en sanidad están transferidas a las diecisiete comunidades y dos ciudades autónomas que lo componen. Esta sanidad descentralizada genera conflictos entre territorios, debido a diferencias en la toma de decisiones, como el ocurrido entre varios presidentes autonómicos y la presidenta de la Comunidad de Madrid, a raíz de que esta flexibilizara las restricciones para favorecer a la hostelería (Mateo, 2021). Asimismo, también provoca tensiones entre los Gobiernos autonómicos y el Gobierno central en relación con los límites de las competencias, la percepción del riesgo, el planteamiento de los problemas y sus eventuales soluciones. Estas discrepancias se polarizan durante la cogobernanza, impulsada por el presidente del Gobierno Pedro Sánchez a principios de mayo de 2020 y que se concreta el 21 de junio (tras la precipitada desescalada), cuando las comunidades recuperan su poder de decisión. La cogobernanza puede entenderse como una estrategia del Gobierno central para minimizar futuras críticas, al trasladar toda la responsabilidad a los Gobiernos autonómicos.

Al no entender de fronteras, el virus ha acentuado más - si cabe- las deficiencias de un Estado de las autonomías desigual, injusto y fundado en los privilegios de unos pocos sobre otros, con un Ministerio de Sanidad exiguo en competencias y recursos, y sin la suficiente capacidad efectiva para coordinar entre sí unos territorios que no trabajan por el bien común, sino por sus intereses privativos. Un ejemplo sangrante de esta descoordinación resultó en que en comunidades con menor incidencia se quedaran sin ocupar 2200 camas de cuidados intensivos; mientras que en otras comunidades con hospitales saturados murieron sin recibir asistencia cerca de 12000 ancianos (Alsedo, 2020). En definitiva, la gestión política de la crisis por unos y por otros siempre ha ido a rebufo del comportamiento del virus, con las consecuencias catastróficas en pérdidas humanas y económicas.

Científicos, periodistas y políticos se refieren a "olas de la pandemia" cuando se produce un incremento de la incidencia acumulada, esto es, un incremento de la proporción de personas que enferman en un periodo concreto. Mientras escribo esto, España está en plena tercera ola, con unas previsiones poco halagüeñas.

1 Según el Ministerio de Sanidad (2020b), durante la primera ola murieron en las residencias casi 20000 ancianos. 


\section{DISERTACIONES}

ENSAYOS

Hasta el momento, el país lleva sufridas tres olas de la pandemia. Entre mediados de marzo y gran parte de abril de 2020 se registra una explosión en los contagios y con ello sobrevino la primera ola que fue inevitable para el Gobierno de coalición y sus medios afines. De hecho, parece que el Gobierno y sus medios afines esgrimen el "argumento de la inevitabilidad" para justificar que la irrupción de la covid-19 en España fue un fenómeno impredecible y que, por consiguiente, sus secuelas sanitarias, sociales y económicas no se debieron a las decisiones tempranas realizadas por el Gobierno central, sino a inesperados, externos y desgraciados acontecimientos. En la actualidad, la tercera ola (pico de la curva sobre el 30 de enero de 2021) se ha superpuesto a la segunda, que se inicia a finales de julio y alcanza su máximo apogeo a principios de noviembre de 2020 (figura 1). La toma de decisiones políticas, tanto en febrero-marzo como en los días previos a las vacaciones de verano y de Navidad, es crucial y puede explicar, por lo menos en parte, la aparición y la magnitud de estas tres olas pandémicas.

\section{Casos por 100.000 los últimos 14 días}

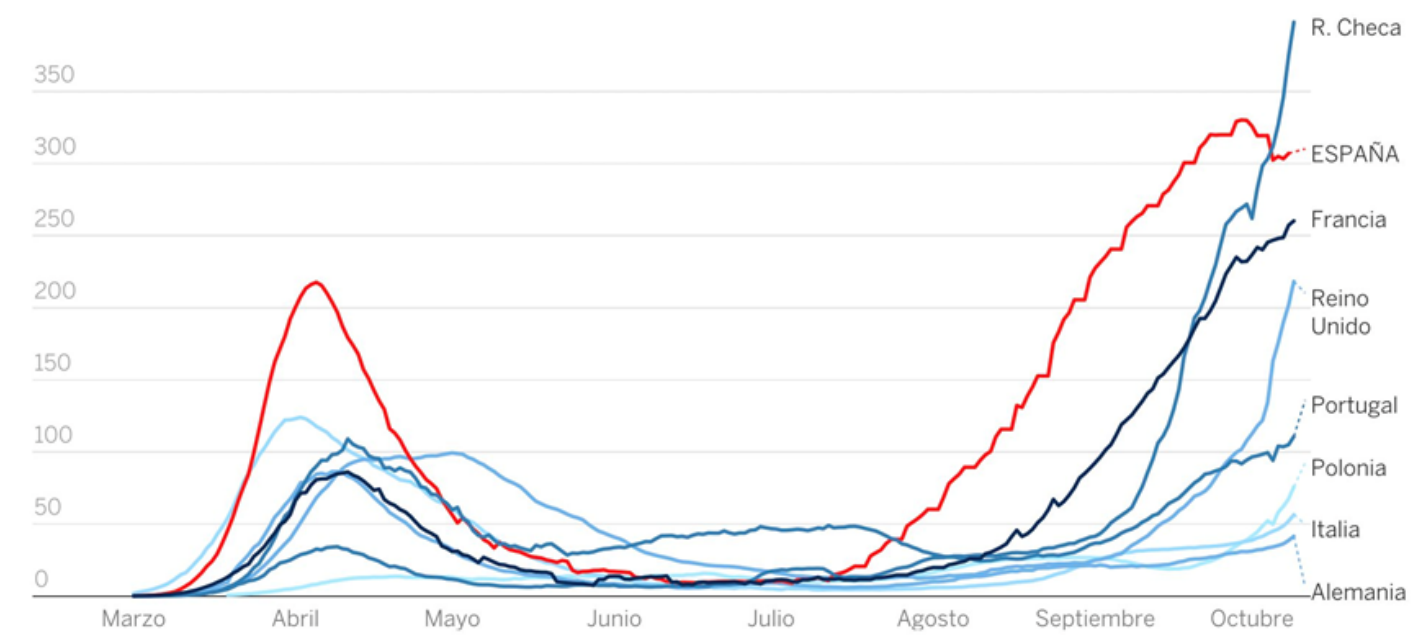

Figura 1. Representación de la primera ola y del pico de la segunda en varios países europeos (en rojo, España)

Fuente: ECDC.

Para una mejor comprensión de lo sucedido en España en los primeros meses, distingo cuatro periodos en la gestión comunicativa de la crisis sanitaria: periodo de inacción, de iniciación, de confinamiento y de desescalada.

1. Periodo de inacción: en el que el Ministerio de Sanidad maneja información científico-técnica procedente de China y de otros países afectados por la covid-19, pero el Gobierno no genera ningún tipo de comunicación pública. Este periodo va del 31 de diciembre de 2019 al 22 enero de 2020.

2. Periodo de iniciación: en el que las autoridades comienzan a proporcionar información pública. Abarca desde el 22 de enero de 2020, con la primera comparecencia del ministro de Sanidad, Salvador Illa, en la que anuncia que España está preparada para afrontar cualquier eventualidad, hasta el 13 de marzo, con 


\section{DISERTACIONES}

ENSAYOS

Comunicación y controversias sociocientíficas en salud y medio ambiente

ISSN: 1856-9536

Doi: https://doi.org/10.12804/revistas.urosario.edu.co/disertaciones/a.10334

Volumen 14, Número 2 / Julio-diciembre 2021

Versión PDF para imprimir desde

http://revistas.urosario.edu.co/index.php/disertaciones

la declaración del "estado de alarma" por parte del presidente del Gobierno. En ese periodo se toman decisiones trascendentes, esenciales para entender la ulterior evolución pandémica. Por una parte, el 2 de marzo el ECDC (2020b) publica un documento en el que plantea los posibles escenarios de riesgo y las recomendaciones que se deben adoptar en cada situación. Por otra parte, el 13 de marzo se declara el estado de alarma por el cual el Gobierno se arroga el "mando único", por lo que las competencias de las autonomías quedan subordinadas a este. Entre medias, el Gobierno aplica las primeras medidas de contención, se producen aglomeraciones multitudinarias en varios lugares de España con el consentimiento gubernativo y la oms declara la pandemia por el SARS-CoV-2.

3. Periodo de confinamiento: en el que el Ejecutivo instaura el confinamiento domiciliario para los ciudadanos, con el consecuente cierre de toda actividad económica no esencial. Además, el Gobierno asume el control de la comunicación y de los flujos informativos. Este periodo comprende del 14 de marzo, con la entrada en vigor del estado de alarma, hasta el 28 de abril, cuando el Gobierno presenta su Plan de desconfinamiento de España.

4. Periodo de desescalada: en el que el Gobierno se esfuerza por comunicar, mediante un discurso triunfalista y eslóganes del tipo "Salimos más fuertes", las nuevas medidas para retornar de manera paulatina a lo que denomina la nueva normalidad. El plan de desescalada consta de cuatro fases, con decisiones desiguales respecto del tiempo (fechas de transición de una fase a otra) y del espacio (dominios geográficos que pasan de una fase a otra). Para lograr esto, el Gobierno establece distintos canales de comunicación con los presidentes autonómicos para ir modulando la velocidad del cambio de fase. Este periodo comienza el 28 de abril y termina el 21 de junio con la nueva normalidad, etapa en la que el Gobierno impulsa la cogobernanza en la gestión de la crisis, se suprimen las restricciones de movilidad, impuestas durante el estado de alarma, aunque siguen vigentes prescripciones de higiene y de distancia social.

La desescalada parece tener un claro objetivo: salvar la temporada turística. Sin embargo, a mediados de julio se constata que la curva de contagios repunta (inicio de la segunda ola). La curva de incidencia acumulada empieza a doblegarse a principios de noviembre, justo unas semanas después de que Pedro Sánchez declare el 25 de octubre un segundo estado de alarma (vigente hasta mayo de 2021). El 10 de diciembre se registra la incidencia más baja alcanzada tras el pico de la segunda ola con 188,62 casos por cada 100000 habitantes; sin embargo, en vísperas de la Nochebuena se supera de nuevo el umbral de riesgo extremo de los 250 casos (Martín Plaza, 2021). La relajación social durante las fiestas navideñas dispara exponencialmente los casos y esta segunda ola se superpone a la tercera. Una de las mayores amenazas en la actual tercera ola es que se convierta en prevalente la denominada cepa británica, una variante del virus original que supone un aumento estimado de entre el $40 \%$ y el $70 \%$ en la transmisibilidad y, tal vez, una mayor letalidad (oms, 2020).

\section{Definiendo las controversias sociocientíficas}

Las controversias sociocientíficas son básicamente un problema de comunicación y, por lo tanto, retórico. Su análisis se ha abordado desde distintas disciplinas, como la educación, la sociología, la filosofía, la retórica o la comunicación.

Definir las controversias sociocientíficas no es tarea fácil. Una aproximación clásica distingue entre controversias cognitivas (o de conocimiento), caracterizadas porque la discusión recae en el estatuto ontológico de las 


\section{DISERTACIONES}

ENSAYOS

ofertas de conocimiento en disputa y porque se circunscriben al dominio de los expertos, y controversias sociales (o de aspectos no científicos), basadas no tanto en el conocimiento tecnocientífico como en disensiones políticas, económicas o éticas que promueve este conocimiento (Engelhardt \& Caplan, 1987). La distinción de Engelhardt y Caplan es de orden epistemológico y se enmarca en una tradición positivista que delimita de manera tajante "lo cognitivo" de "lo social".

Para trascender esta dicotomía epistemológica, Aibar (2002) clasifica las controversias en función del ámbito social en el que surgen y no tanto de las diferencias epistemológicas entre un componente cognitivo y otro social. De esta manera, las controversias tecnocientíficas en sentido estricto se originan y desarrollan en foros rigurosamente especializados, como laboratorios, encuentros, revistas de investigación, etc. Por su parte, las controversias tecnocientíficas públicas van más allá del núcleo cerrado de los expertos para instalarse en los foros públicos: parlamentos, medios de comunicación, tribunales de justicia, etc.

En la misma línea, Echeverría (2003) opone las controversias científicas y las contiendas tecnocientíficas sobre la base de diferencias entre la ciencia moderna y la tecnociencia. Las primeras están enmarcadas dentro de la ciencia académica; mientras que las segundas trascienden la noción de controversia, porque son verdaderas contiendas que involucran conflictos políticos, económicos, jurídicos, sociales e, incluso, militares. Las contiendas tecnocientíficas, además de en los escenarios estrictamente académicos, se desarrollan en otros muchos, "como los mercados, las empresas, los despachos e instituciones políticas, los medios de comunicación y, a veces por desgracia, también en el campo de batalla" (Echeverría, 2003, p. 180). Aquí se libran las más agrias disputas entre los actores sociales en conflicto (gobierno, oposición, medios de comunicación, ciudadanos, creadores de contenidos en redes sociales, activistas, etc.). Así, es necesario considerar en dichas controversias cuatro facetas mínimas: la social, la económica, la tecnológica y la epistémica.

Las clasificaciones de Aibar y Echeverría son de orden sociológico y se inscriben dentro de un paradigma crítico. Como la frontera entre lo científico y lo social es porosa, "socioscientific controversies might then be described as extended argumentative engagements over socially significant issues and comprising communicative events and practices in and from both scientific and nonscientific spheres" (Stewart, 2009, p. 125).

El alcance de dichas controversias es diverso. Pueden abarcar décadas, como la polémica entre evolucionismo y creacionismo en la enseñanza estadounidense o seguir el patrón diario de un acontecimiento noticioso puntual. Pueden surgir cuando una nueva técnica suscita recelos éticos, como la clonación de mamíferos por transferencia nuclear (Alcíbar, 2007). Pueden darse cuando el origen de la crisis es indeterminado, acarrea la pérdida de vidas humanas o existen discusiones sobre la responsabilidad política de su gestión (Graham \& Walsh, 2019), como es el caso de la covid-19. Y, por último, pueden tener un alcance local o global; sin duda, la crisis global por antonomasia en 2020 (y lo que llevamos de 2021) ha sido y es la pandemia de la covid-19, una de las más complejas controversias sociocientíficas de la historia.

\section{Algunos debates públicos relevantes suscitados por la pandemia}

En las páginas siguientes, esbozo algunos debates públicos suscitados por la pandemia de la covid-19. Los dos primeros (economía frente a salud, y confianza y credibilidad en las instituciones) se ciñen a la gestión política de la crisis sanitaria en España; el tercer debate (origen del SARS-CoV-2) tiene alcance internacional. 


\section{DISERTACIONES}

ENSAYOS

\section{Debate 1. Economía frente a salud}

Si asumimos que sin salud no hay economía, el debate economía frente a salud podría parecer estéril. Sin embargo, la pandemia ha promovido un acalorado debate público en torno a esta dicotomía. Así, unos actores sociales esgrimen argumentos a favor de la salud; mientras que otros lo hacen a favor de la economía o de procurar el equilibrio entre ambas.

Según el barómetro del Centro de Investigaciones Sociológicas de octubre de 2020, los españoles están más preocupados por los efectos de la crisis sobre la salud $(40,9 \%)$ que sobre la economía y el empleo $(23,4 \%)$. Pero ¿cuáles son las prioridades de los políticos en el debate economía/salud? Y ¿las de los expertos?

En general, el marco de actuación de los responsables políticos españoles para evaluar la situación y comunicar el riesgo de la pandemia de la covid-19 ha sido y es inadecuado. A pesar de que en los inicios de la crisis sanitaria dispone de información procedente de la oms, de China y, sobre todo, de un país tan próximo geográfica y culturalmente como Italia, el Gobierno de España reacciona tarde y mal. En la segunda, y en la actual tercera ola, las autoridades gubernativas han seguido cometiendo graves errores. Tanto Gobierno como oposición realizan continuamente cálculos electoralistas para evaluar los réditos políticos de sus declaraciones, que no siempre tienen un correlato con las decisiones que toman. De hecho, el 5 de octubre 55 sociedades científicas, representantes de más de 170000 profesionales sanitarios, firman el manifiesto "En la salud, ustedes mandan pero no saben", dirigido al presidente del Gobierno y a los presidentes autonómicos, en el que instan a los políticos a abandonar el enfrentamiento partidista y aunar recursos y esfuerzos para enfrentar la pandemia con criterios comunes de base exclusivamente científica.

En función de la coyuntura socioeconómica y política, algunos políticos del Gobierno o próximos a este suelen mantener posturas ambivalentes. Por ejemplo, a las pretensiones de la presidenta de la Comunidad de Madrid, Isabel Díaz Ayuso (perteneciente al principal partido de la oposición), de recuperar lo antes posible "una o dos horas" del toque de queda -vigente entre las 22.00 y las 6.00 horas - para no seguir "perjudicando a la economía", el portavoz en el Senado del grupo socialista (partido principal en el Gobierno de coalición), Ander Gil, le advierte que "la vida y la salud de los ciudadanos deben estar por encima de la economía" (EFE, 2021). Semejante declaración de principios no deja lugar a dudas sobre el compromiso del principal partido del Gobierno con la salud de los ciudadanos, aunque en su declaración institucional del 25 de octubre de 2020, tras el consejo de ministros extraordinario que decreta el segundo estado de alarma, Pedro Sánchez apuesta decididamente por implementar medidas que tiendan al equilibrio entre la economía y la salud: "[...] nuestro objetivo es uno: es doblegar la curva de la segunda ola, igual que doblegamos la de la primera ola. El coste de vidas debe ser el menor posible, pero también debemos proteger nuestra actividad económica y laboral y preservar en la medida de nuestras posibilidades el ritmo de nuestras vidas". ${ }^{2}$

2 Transcripción de la intervención de Pedro Sánchez (2020). Disponible en: https://www.lamoncloa.gob.es/ consejodeministros/Paginas/EnlaceTranscripciones2020/251020-presidente.aspx 


\section{DISERTACIONES}

\section{ENSAYOS}

Así, las declaraciones de miembros del partido socialista, mayoritario en el Gobierno, cambian según se efectúen en un contexto institucional o mediático, oscilando entre la defensa acérrima de la salud frente a la economía y la armonización de ambas.

Por su parte, los representantes del principal partido de la oposición, el Partido Popular, se decantan por un discurso más uniforme en el que se defiende la protección de la economía, so pena de que las muertes por hambre superen a las causadas por el propio virus. Ante las restricciones decretadas por el Gobierno en el segundo estado de alarma, el portavoz del Partido Popular en Sevilla, Beltrán Pérez, asevera que "es necesario equilibrar salud y economía comprometiéndose con los que peor lo van a pasar", en clara referencia a las personas de sectores tan afectados como el comercio y la hostelería (Europa Press, 2020b).

Como se ha dicho antes, los anuncios del Gobierno son líquidos; pero no sus acciones. La imprevisión (hospitales desprovistos de respiradores y de diverso material sanitario, como equipos de protección individual y mascarillas), el grave error en la estimación de las consecuencias de la pandemia en territorio español, a pesar del ejemplo italiano (v. la acumulación de casos en la región de Lombardía, a partir del 21 de febrero de 2020), la masificación en los transportes públicos y la insensatez de consentir la celebración de concentraciones multitudinarias (entre las más notables, el encuentro de fútbol entre el Atalanta y el Valencia el 19 de febrero, el mitin del partido Vox en Madrid y las múltiples manifestaciones feministas del 8 de marzo), parece haber influido decisivamente en el aumento exponencial de los contagios que desemboca en la primera ola de la pandemia y en que el Gobierno declare el primer estado de alarma, el 14 de marzo (v. periodo de iniciación). En un reciente estudio auspiciado por la Fundación de Estudios de Economía Aplicada, Orea y Álvarez (2020) concluyen:

Según nuestras simulaciones, el número de casos confirmados en la España peninsular hubiera aumentado, en ausencia de estado de alarma, de 126 a 617 mil casos a fecha de 4 de abril de 2020. Con dicha medida, por tanto, se han evitado alrededor de 491 mil infecciones confirmadas, lo que representa una reducción media del $79.5 \%$ en el número de contagios potenciales. Sin embargo, nuestras simulaciones ponen también de manifiesto que se hubiera podido ahorrar un número aún mayor de contagios $\mathrm{y}$, por consiguiente, de fallecimientos, si las medidas de control asociadas a la declaración de alarma se hubiesen puesto en marcha con solo una semana de antelación. El número de casos confirmados hubiera pasado a 47 mil, menos de la mitad [de] los confirmados a fecha de 4 de abril. Señalar finalmente que tal disminución hubiera evitado probablemente el colapso de muchos hospitales en nuestro país. (pp. 3 y 4; las cursivas son mías)

En la misma línea se sitúa un recentísimo estudio realizado por investigadores de la Universidad Rovira i Virgili de Barcelona y de la Universidad de Zaragoza. Llegan a la conclusión que de haberse confinado a la población española siete días antes (sobre el 6 o 7 de marzo de 2020) se habrían salvado más de 20000 vidas (Fita \& Villalonga, 2021). ${ }^{3}$

3 Según datos agregados y notificados por la Comunidad de Madrid, el 8 de marzo de 2020 ya se habían registrado 1003 casos, 56 pacientes en unidades de cuidados intensivos y 16 fallecidos. 


\section{DISERTACIONES}

ENSAYOS

Comunicación y controversias sociocientíficas en salud y medio ambiente

ISSN: 1856-9536

Doi: https://doi.org/10.12804/revistas.urosario.edu.co/disertaciones/a.10334

Volumen 14, Número 2 / Julio-diciembre 2021

Versión PDF para imprimir desde

http://revistas.urosario.edu.co/index.php/disertaciones

Ante este inquietante panorama, el Gobierno central decreta el estricto encierro domiciliario y la suspensión total de la actividad económica no esencial (v. periodo de confinamiento). La clausura tiene un demoledor efecto para la economía del país: acarrea la destrucción de unas 68000 empresas, de las cuales el $99 \%$ tiene menos de 50 trabajadores en plantilla (Velarde, 2020). Además, según el Instituto Nacional de Estadística, la economía española se desplomó un $17,8 \%$ en el segundo trimestre de 2020 (Maqueda, 2020).

Pese a que hay voces en el Gobierno que califican al sector turístico de precario y de tener poco valor añadido (Villaécija, 2020), lo cierto es que este representa el 12,5\% del producto interior bruto nacional. De hecho, es tan esencial para la economía nacional que el Gobierno instaura la nueva normalidad y con ello afloja las restricciones (v. periodo de desescalada), en un intento por salvar la campaña estival. La relajación normativa preocupa a algunos expertos que alertan del peligro de contagios descontrolados tras el verano. El Gobierno desoye tales avisos y a mediados de julio de 2020, en pleno verano, la curva de incidencia acumulada comienza a subir, adelantándose en España la segunda ola, que llega meses después a otros países europeos.

Las críticas se exacerban conforme evoluciona la pandemia. Si en los inicios de la primera ola (periodos de inacción y de iniciación) las críticas de los expertos ya son visibles, durante el periodo de desescalada son duras y se vuelven ásperas tras el verano y, sobre todo, en los días previos y ulteriores a las vacaciones de Navidad de 2020. Para muchos expertos independientes, el discurso que prioriza la economía sobre la salud no atiende a criterios científicos. Veamos tres ejemplos ilustrativos.

Álvaro Castellanos, director del Área de Medicina Intensiva del Hospital La Fe de Valencia, aduce que se ha ido siempre por detrás de la pandemia y que "la búsqueda de un equilibrio entre efecto económico y efecto salud es un objetivo muy inestable, es un enfoque poco científico cuyo resultado final puede ser negativo para ambos, economía y salud" (Guindo, 2020). El jefe del servicio de urgencias del Hospital Universitario Ramón y Cajal de Madrid, César Carballo, exclama indignado en televisión: "¿Qué pasa en este país? Hemos puesto en una balanza euros y muertes y ganan los euros" (Horizonte, 2021). Por su parte, Miguel Hernán, epidemiólogo de la Universidad de Harvard, afirma:

Lo que no puede ser es que se hayan tomado decisiones para salvar la economía sin un debate transparente sobre su impacto sobre la salud pública. ¿Cómo miramos hoy a la cara a nuestros trabajadores sanitarios cuando, en periodos de incidencia aún manejable, dejamos los bares abiertos sin tomarnos en serio el rastreo de contactos? (Gómez, 2021, s. p.)

En efecto, como demuestran los hechos, la estrategia de salvar la economía sin preocuparse por ampliar el número y eficacia de los rastreadores, reforzar la atención primaria en los centros de salud o imponer controles más efectivos en los aeropuertos está destinada al fracaso, tanto en términos de vidas humanas perdidas como de perjuicios económicos.

En resumen, por mor de su indolencia y falta de previsión, el Gobierno, en marzo de 2020, se ve abocado a ejecutar medidas draconianas para salvar el máximo número de vidas. Tras la primera ola, tanto el Gobierno central como los Gobiernos autonómicos anteponen la economía a la salud, sea de una forma abierta (típica de neoliberales) o disimulada (típica de socialistas). Y esto es así porque no les queda otra: dado que la gestión ha ido en todo momento a rebufo del SARS-CoV-2, se adoptan estrategias orientadas a coexistir con el virus (de ahí la preeminencia de los criterios economicistas o ideológicos), en vez de estrategias orientadas a erradicar el virus (basadas en criterios técnicos, como han demostrado países como Singapur, Corea del Sur, Australia, entre otros). Los expertos independientes, por su parte, suelen mantener un discurso más centrado en la premisa "no hay economía sin salud". 


\section{DISERTACIONES}

ENSAYOS

\section{Debate 2. Confianza y credibilidad en las instituciones}

El sociólogo alemán Ulrich Beck acuña en 1986 el concepto de sociedad del riesgo para referirse a la sociedad contemporánea en la que no es posible atribuir con claridad el riesgo a una causa externa. A diferencia de la sociedad preindustrial, en la que el riesgo proviene de fuera, la sociedad actual se enfrenta a sí misma en su forma de gestionar el riesgo: "risks are the reflection of human actions and omissions, the expression of highly developed productive forces. This means that the sources of danger are no longer ignorance but knowledge" (Beck, 1992, p. 183; énfasis en el original).

Las estrategias de gestión de la pandemia están siendo desiguales en los distintos países, lo cual conlleva un desigual impacto social y económico en cada uno de ellos. Los países con mejor capital social y más coherencia institucional responden de manera más efectiva a las emergencias, sustentan gobiernos más robustos y creibles $y$, en definitiva, insuflan mayor confianza en el ciudadano.

El Gobierno español ha tenido una presencia pública constante para ofrecer información, de acuerdo con una estrategia encaminada a acaparar y encuadrar los temas y a establecer una retórica bélica mediante la cual transmitir a la población la sensación de unidad. Pero, a pesar de las continuas apariciones públicas, la interacción real con la ciudadanía ha sido ineficiente (Castillo-Esparcia et al., 2020). El uso de la retórica bélica por parte del Gobierno es especialmente interesante. Pedro Sánchez explota la puesta en escena y la jerga militar en sus primeras ruedas de prensa de marzo y abril de 2020 para, más tarde, el 25 de octubre, una vez declarado el segundo estado de alarma, renegar de ella. En esas primeras apariciones públicas, el presidente del Gobierno apela a la unidad nacional ante una situación de guerra contra un enemigo tan invisible como letal. La retórica bélica le permite exigir de la población disciplina y responsabilidad y, a la par, arrogarse el mando único, algo que no es fácil en un país tan descentralizado y con arraigados conflictos territoriales como España. Ahora bien, después de su declaración institucional del 25 de octubre, y ya en el turno de preguntas periodísticas, el presidente exhorta a los medios a que abandonen la expresión toque de queda y la sustituyan por otra de nuevo cuño, restricción de la movilidad nocturna. Según Pedro Sánchez, esta expresión es “más contemporánea” y evita las connotaciones castrenses que tiene "toque de queda" para las generaciones anteriores.

Esto no es baladí. Apunta a una burda manipulación del lenguaje con fines propagandísticos. El filósofo y académico de la Real Academia Española, Félix de Azúa, lo explica con mucha elocuencia cuando asegura que:

[...] el gobierno de "progreso" está persuadido de que los técnicos en publicidad son los mejores consejeros políticos. Cree con una fe de carbonero en el marketing. Y esto es así porque sabe que lo que vende no tiene ningún fundamento moral o intelectual. Son productos comerciales y de consumo. Una posición ultracapitalista muy propia de un gobierno "progresista". (Ramírez, 2020)

En este sentido, la confianza y la credibilidad cobran relieve en la gestión de la comunicación del riesgo. La transparencia debe ser la seña de identidad, si lo que se desea es crear confianza y ganar en credibilidad o, si se han perdido, recuperarlas. Como la gestión política se somete a un riguroso escrutinio por parte de la opinión pública, las estrategias de comunicación opacas, además de ir en detrimento de los intereses de los ciudadanos, también pueden convertirse en un búmeran contra el gestor. La honestidad percibida y la difusión completa de información son elementos clave para determinar la confianza entre el público (Miller, 2016). 


\section{DISERTACIONES}

ENSAYOS

Comunicación y controversias sociocientíficas en salud y medio ambiente

ISSN: 1856-9536

Doi: https://doi.org/10.12804/revistas.urosario.edu.co/disertaciones/a.10334

Volumen 14, Número 2 / Julio-diciembre 2021

Versión PDF para imprimir desde

http://revistas.urosario.edu.co/index.php/disertaciones

Sin embargo, la gestión política en España no se ha caracterizado precisamente por ser un modelo de transparencia. Los ejemplos de opacidad durante la gestión de la pandemia son muchos y diversos, así que únicamente me referiré a unos pocos.

Desde el principio de la crisis, el Gobierno organiza sus apariciones públicas cribando las preguntas de los periodistas. Más de 400 periodistas de todos los medios denuncian esta maniobra de control informativo y suscriben el manifiesto "La libertad de preguntar", apoyado por la Asociación de la Prensa de Madrid y la Federación de Asociaciones de Periodistas de España (Caro, 2020). La Secretaría de Estado de Comunicación reacciona a las pretensiones de los periodistas rechazando la eliminación del filtro impuesto por el Gobierno en las ruedas de prensa, pero es tal la avalancha de protestas que se ve obligada a rectificar $\mathrm{y}$, a la postre, permitir las preguntas de los periodistas por videoconferencia (Piña, 2020).

Por otra parte, la descoordinación entre Gobierno central y Gobiernos autonómicos, sumado a los errores de comunicación del director del Centro de Coordinación de Alertas y Emergencias Sanitarias del Ministerio de Sanidad, Fernando Simón, no solo socava la credibilidad de las autoridades sanitarias, sino que también debilita la confianza en el Gobierno. Como muestra ilustrativa, a continuación, expongo dos de los errores más graves cometidos por Simón, máxima autoridad científica en emergencias sanitarias del Gobierno español.

El primero de ellos -y quizá el más conspicuo- se produce en la rueda de prensa del 31 de enero de 2020 (v. periodo de iniciación) en la que dijo literalmente: "Nosotros creemos que España no va a tener como mucho más allá de algún caso diagnosticado, esperamos que no haya transmisión, si la hay será transmisión muy limitada y muy controlada". ${ }^{4} \mathrm{Si}$ se confronta su optimista augurio con los datos oficiales del propio Ministerio de Sanidad a 5 de febrero de 2021 (61386 muertos), Simón queda totalmente en evidencia (Ministerio de Sanidad, 2021).

Otra de sus declaraciones más polémicas es haber minimizado el efecto futuro de la "cepa británica" en España. En la rueda de prensa del 11 de enero de 2021, Simón afirma que "el impacto de la variante, en caso de tener algún impacto, será marginal en nuestro país". ${ }^{5}$ El verbo (será) indica que la variante británica no solo es marginal en España en el momento de emitir esas palabras, sino que también lo será en el futuro. Justo diez días después, Simón se autocorrige: "Las expectativas que tenemos, si evolucionara como ha evolucionado en Reino Unido y en Irlanda, estaríamos esperando que fuera una cepa dominante, que podría llegar alrededor del 40-50\% de ocupación de espacio aproximadamente hacia mediados del mes de marzo" [sic]. ${ }^{6}$ De suponer el 11 de enero que la variante británica sería marginal en España, el 21 de enero Simón admite que podría llegar a ser la hegemónica a mediados de marzo.

El catedrático de Bioquímica y Biología Molecular de la Universidad Complutense de Madrid, José Manuel Bautista, critica a Simón por restar importancia al impacto de la variante británica en España y se lamenta de que ver sus comparecencias públicas es como ver un anuncio de coches que nadie va a comprar: "No tiene autoridad,

4 Transcripción de la rueda de prensa (v. 16’40"). Disponible en: https://www.mscbs.gob.es/gabinete/ audios.do?metodo=verAlbum\&album $=202001$

5 Rueda de prensa de Fernando Simón el 11 de enero de 2021. Disponible en: https://www.youtube.com/ watch?v=PFEiQ4q63ls\&t=254s

6 Rueda de prensa de Fernando Simón el 21 de enero de 2021. Disponible en: https://www.youtube.com/ watch?v=shilLg2EGwo 


\section{DISERTACIONES}

ENSAYOS

Comunicación y controversias sociocientificas en salud y medio ambiente

ISSN: 1856-9536

Doi: https://doi.org/10.12804/revistas.urosario.edu.co/disertaciones/a.10334

Volumen 14, Número 2 / Julio-diciembre 2021

Versión PDF para imprimir desde

http://revistas.urosario.edu.co/index.php/disertaciones

porque él mismo la ha ido perdiendo. Puso en duda el uso de las mascarillas, la transmisión del virus por aerosoles [...] Predice muy mal y es poco cuidadoso porque hace aseveraciones que en el ámbito científico se evitarían hacer" (Stegmann, 2021).

Como sugiere el nombre del organismo que dirige, Simón debe trabajar para coordinar las medidas de contención de la enfermedad, alertar de sus previsibles derivaciones y, en consecuencia, adelantarse a las evoluciones del SARS-CoV-2. Por el contrario, la mayoría de las veces actúa como un simple portavoz epidemiológico que, en momentos clave, incurre en gruesas equivocaciones cuando se aventura a dar pronósticos.

Otra muestra de falta de transparencia es la que ponen de manifiesto varios investigadores en una carta publicada en línea el 9 de octubre de 2020, en The Lancet (Trias-Llimós et al., 2020). En ella denuncian la imprecisión en el registro de los datos y exigen a las autoridades sanitarias que publiquen de forma clara y abierta las actualizaciones diarias "sobre pruebas, casos, hospitalizaciones, ingresos a unidades de cuidados intensivos, recuperaciones y muertes, incluidas las correcciones de series retrospectivas en curso". Y, además, que estas variables se desglosen por edad, sexo y ubicación geográfica, con objeto de "monitorear mejor los impactos demográficos de la pandemia y para informar mejor una respuesta de salud pública".

Otro factor que mengua la credibilidad y la confianza en las instituciones es el exceso de triunfalismo. Cuando los logros son pírricos, no se muestra autocrítica o se carece de suficiente perspectiva para ser optimista, las peroratas triunfalistas hacen un flaco favor a la credibilidad gubernativa y, por ende, la confianza del ciudadano en sus instituciones se resiente. En un contexto tan negativo como el pandémico, un discurso en exceso triunfalista denota falta de liderazgo, agravio a la inteligencia del ciudadano adulto y una concepción infantiloide de la sociedad. Como consecuencia, muchos ciudadanos tienden a cuestionar la capacidad del Gobierno para afrontar con seriedad la gestión de la crisis.

Tras el severo confinamiento de la primera ola ( $v$. periodo de confinamiento) y el anuncio de la nueva normalidad (v. periodo de desescalada), la maquinaria propagandística del Gobierno se pone en marcha, sin haber tomado medidas rigurosas de control de posibles nuevos brotes. El profesor en Medicina Preventiva y Salud Pública en la Universidad de Alcalá, Pedro Gullón, entiende que la desescalada se produce sin un plan integral para rastrear y realizar pruebas PCR y en un ambiente político caracterizado por la disputa y la falta de unidad; esta precipitación acarrea que en ciertas regiones se aceleren de nuevo los contagios. "Con más PCR y más rastreadores, podríamos haber controlado mejor los primeros brotes" (Soto, 2020). Pero, para el Gobierno, lo prioritario es proclamar que el virus ha sido derrotado.

Cuando la curva de incidencia de casos por 100000 habitantes decae, pero aún no hay motivos para sacar pecho, el Gobierno lanza una campaña institucional con el eslogan "Salimos más fuertes", que aparece el 25 de mayo de 2020 en la portada de los principales periódicos del país (figura 2). Ese mismo día, Pedro Sánchez publica en su cuenta de Twitter: "Lo hemos conseguido, gracias al esfuerzo y responsabilidad de todas y todos hemos llegado hasta aquí. Sois vosotros los que habéis hecho retroceder al virus. España inicia con pie firme la transición hacia la Nueva Normalidad. \#SalimosMásFuertes \#EsteVirusLoParamosUnidos". 


\section{DISERTACIONES}

ENSAYOS

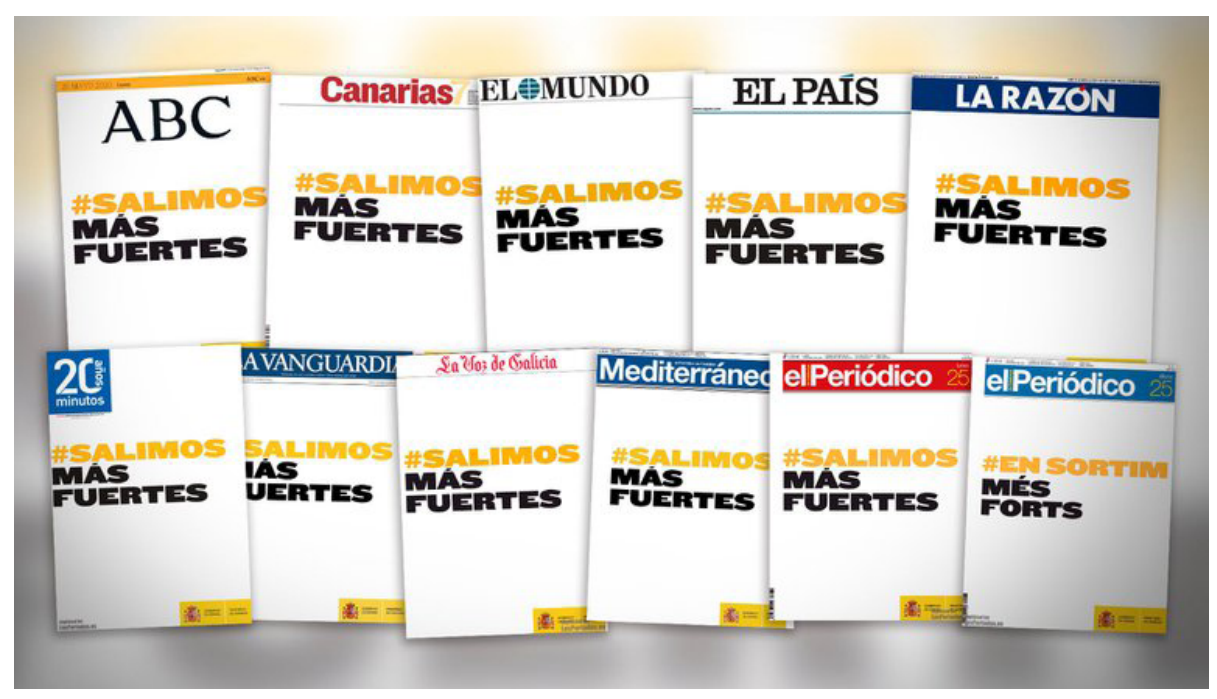

Figura 2. Portadas de los principales periódicos españoles del 25 de mayo de 2020 con el eslogan gubernamental "Salimos más fuertes"

Fuente: Twitter

El 10 de junio, el presidente del Gobierno en respuesta al líder de la oposición, Pablo Casado, afirma desde la sede parlamentaria: “[...] todos los grupos parlamentarios y el conjunto de ciudadanía española hemos vencido al virus" (Cortes Generales, 2020). Ese mismo día, Sanidad notifica 167 casos diagnosticados el día previo y 40 fallecidos en la última semana (Ministerio de Sanidad, 2020). Este mantra triunfalista lo repite Sánchez en varias ocasiones; por ejemplo, en un mitin en Bilbao el 5 de julio dice: "Hemos derrotado al virus y controlado la pandemia y doblegado la curva porque el Gobierno de Euskadi y España hemos trabajado juntos y unidos" (Socialistas Vascos, 2020, min. 40).

En definitiva, una gestión comunicativa poco diáfana y capciosamente optimista puede conducir a la desconfianza pública hacia quienes ocupan puestos de autoridad. Si a la falta de transparencia se le añade una retórica triunfalista en un contexto de crisis poco propicio para la tranquilidad, la credibilidad institucional puede quedar en entredicho.

\section{Debate 3. El origen del SARS-CoV-2}

A pesar de que en la actualidad se conoce bastante de la estructura y del genoma del SARS-CoV-2, su origen aún está lejos de estar resuelto. Tampoco se ha esclarecido el origen del brote. Hay consenso científico en que el SARSCoV-2 es un producto zoonótico, es decir, un patógeno, en este caso un virus, que se transmite de forma natural y bidireccional entre animales (en su mayoría vertebrados) y humanos (v. Andersen et al., 2020). Sin embargo, aún hay sombras en cuanto a la naturaleza del reservorio original y, sobre todo, del hospedador intermedio. Muchos estudios sugieren que el virus tiene su origen en el murciélago de herradura, aunque su transmisión directa a los humanos no está clara (v. Boni et al., 2020). 


\section{DISERTACIONES}

ENSAYOS

Actualmente, la hipótesis más plausible es la transmisión indirecta, esto es, el murciélago de herradura es el reservorio original y un animal aún no identificado es el hospedador intermediario, en cuyo interior el nuevo coronavirus habría mutado hasta convertirse en infectivo para el ser humano (figura 3). Para otros coronavirus similares al SARS-CoV-2 sí se conoce el hospedador intermediario: en el SARS-CoV es la civeta de las palmeras y en el MERS-CoV es el dromedario. Se ha especulado con que el pangolín sea este intermediario (Lam et al., 2020); pero lo cierto es que de momento es un enigma. No obstante, varios investigadores descartan como candidatos a hospedador intermediario a las serpientes, aves, civeta de las palmeras y otros animales carnívoros, pangolín y ganado, sugiriendo que los roedores podrían desempeñar un importante papel en la transmisión viral (Yuan et al., 2020).

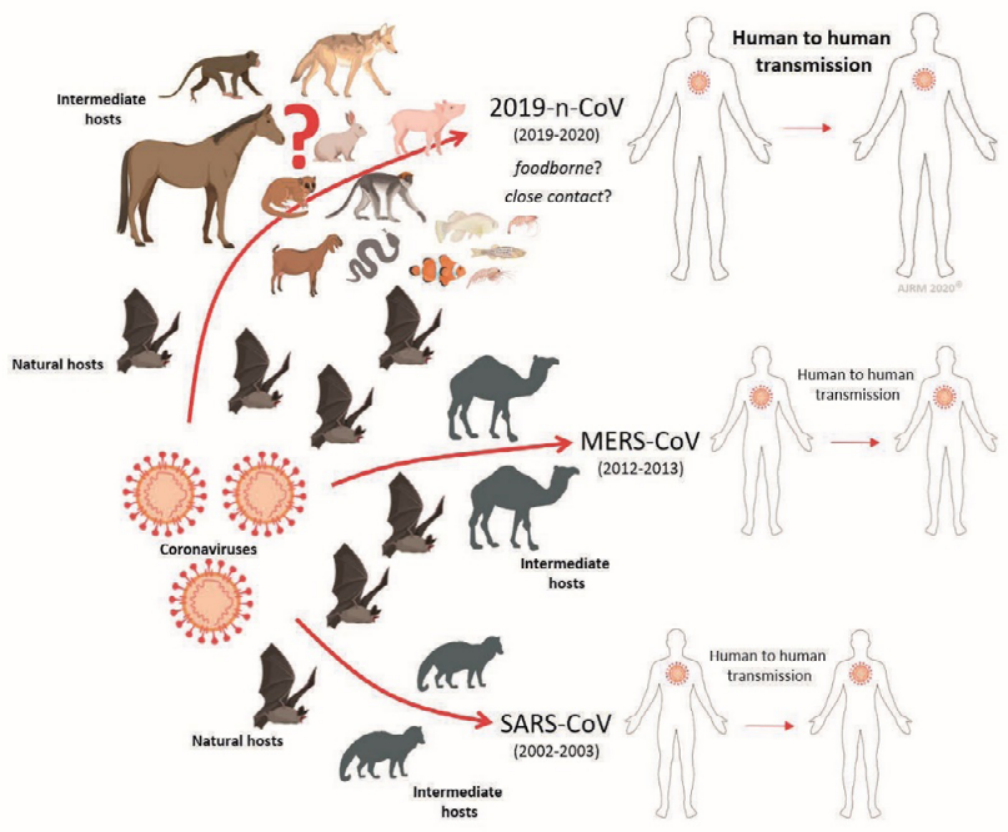

Figura 3. Enfermedades virales transmitidas por murciélagos. En el caso del SARS-CoV-2 o 2019-n-CoV, el hospedador intermedio es una incógnita

Fuente: Rodríguez-Morales et al. (2020).

Otros científicos destacan la falta de evidencia científica sólida sobre el origen del primer brote epidémico, el papel del murciélago de herradura como reservorio del virus y la identidad del hospedador intermedio (Juste Ballesta et al., 2020). Para estos, la única evidencia incuestionable es que el SARS-CoV-2 proviene de un animal.

Después de un año desde que se iniciara la epidemia, y tras varios obstáculos burocráticos, el Gobierno chino autoriza a un equipo de expertos de la oms su desplazamiento hasta Wuhan para dilucidar, entre otros asuntos, el origen del nuevo coronavirus (Vidal Liy, 2021a). Aunque la hipótesis de partida de la misión de la oms es que el origen del SARS-CoV-2 es una zoonosis (de ahí que sus primeras pesquisas se centren en el mercado de Huanan, del que se cree surge el nuevo coronavirus), no descarta que el virus pudiera haberse escapado fortuitamente del 


\section{DISERTACIONES}

ENSAYOS

Comunicación y controversias sociocientificas en salud y medio ambiente

ISSN: 1856-9536

Doi: https://doi.org/10.12804/revistas.urosario.edu.co/disertaciones/a.10334

Volumen 14, Número 2 / Julio-diciembre 2021

Versión PDF para imprimir desde

http://revistas.urosario.edu.co/index.php/disertaciones

Instituto de Virología de Wuhan, en cuyos laboratorios de máxima seguridad se trabaja con coronavirus. En declaraciones el 3 de febrero a la cadena de televisión británica Sky News, uno de los miembros de la oms, el zoólogo británico y experto en ecología de enfermedades, en particular en zoonosis, Peter Daszak, afirma que la hipótesis de la fuga está sobre la mesa y que tienen la mente abierta a cualquier escenario (Cheshire, 2021). Pero, horas más tarde, el jefe de la delegación, Peter Ben Embarek, declara que las especulaciones sobre una posible fuga del coronavirus de un laboratorio pueden dar lugar a "excelentes guiones para películas y series", pero no para más (AFP/EFE, 2021).

Tras terminar sus pesquisas de cuatro semanas en China, el equipo de la oms concluye que el SARS-CoV-2 es de origen animal y descarta como "extremadamente improbable" el que se escapara de un laboratorio, pero sugieren que el brote no empieza en el mercado de Wuhan. En definitiva, la investigación de la oms no esclarece la identidad del animal que actúa como hospedador intermediario, el lugar exacto en el que aparece el virus (no está claro que sea Wuhan), el mecanismo por el que surge o la identidad de la primera persona que se contagia por contacto directo con el vector intermedio (Vidal Liy, 2021b).

Por otra parte, la controversia sobre el origen del SARS-CoV-2 ha derivado en una tensión geopolítica entre Estados Unidos y China, por una parte, y entre Japón y China, por la otra. Tanto Estados Unidos como Japón culpan a China de no haber controlado el brote en su territorio (Europa Press, 2020a). Donald Trump, incluso, llega a acusar a China de haber manipulado artificialmente el virus y le exige que pague indemnizaciones por su negligencia.

La incertidumbre sobre la identidad del hospedador intermedio también ha propiciado toda clase de conjeturas acerca del origen del virus. Estas especulaciones han sido el caldo de cultivo para que medren las teorías conspiranoicas (acrónimo formado a partir de conspira[tivo] y [para]noico). Si bien estas suelen carecer de base científica, lo cierto es que producen mucho ruido mediático. Al margen de los increyentes en la existencia del coronavirus, hay otras personas que abonan ideas conspirativas para amparar un origen artificial del SARS-CoV-2 y, en consecuencia, para tildar al Gobierno chino de ser el responsable de haber creado el virus para su uso militar como arma biológica. Para los conspiranoicos, el origen de la pandemia solo puede explicarse si se acepta que el SARS-CoV-2 se ha inoculado de forma deliberada o se ha escapado accidentalmente de un laboratorio militar secreto. Sin embargo, tanto la investigación académica (v. Andersen et al., 2020) como las (eso sí, cuestionadas) indagaciones de los expertos de la oms parecen indicar que tales especulaciones son infundadas.

\section{Conclusiones}

La gestión de la pandemia en España por parte de los representantes gubernativos deja mucho que desear. Es uno de los países más castigados por la covid-19, porque la gestión de la crisis sanitaria, social, política y económica no está a la altura de tamaño desafío.

La controversia sociocientífica de la covid-19 tiene muchas derivaciones. He pretendido aproximarme, si quiera de una manera inevitablemente parcial, a tres de los debates relevantes asociados a la pandemia: la dicotomía economía/salud, la credibilidad institucional y, como consecuencia, la confianza de los ciudadanos en sus instituciones y, por último, aunque no menos importante, el origen del SARS-CoV-2. Soy consciente de que otros debates igualmente significativos quedan fuera de mis reflexiones. Cuestiones como el análisis de los vínculos y conflictos entre farmacéuticas y Estados con respecto a la producción, comercialización y distribución de las vacunas, así 


\section{DISERTACIONES}

ENSAYOS

como la politización de la ciencia, en concreto, las similitudes y diferencias entre expertos adscritos a organismos gubernamentales y expertos independientes, requerirán investigación futura.

En este artículo me he centrado en la comunicación de la crisis por parte de las autoridades. Creo que, como mínimo, podemos extraer tres lecciones sobre la gestión política de la pandemia: 1) la necesidad de una respuesta global a la crisis sanitaria (máxime cuando hace unas pocas semanas comenzó la vacunación. Si esta no tiene vocación universal, los esfuerzos por alcanzar la ansiada inmunidad de grupo puede que sean inútiles); 2) la necesidad de que en España se centralicen las competencias en materia sanitaria o, en su defecto, establecer una mejor y más efectiva coordinación entre los diferentes estamentos administrativos del Estado, hoy por hoy muy precaria, y 3) la necesidad de elaborar un plan de comunicación riguroso, coordinado, serio y transparente.

Dadas las diferentes estrategias para gestionar el impacto de la covid-19 en los distintos países -algunos han mostrado ser más proactivos y otros más reactivos-, es prioritario abordar estudios comparativos que permitan dilucidar cuáles son los factores estructurales y coyunturales que minimizan o agravan los efectos perniciosos de la expansión del SARS-CoV-2. Sin duda, se trata de un trabajo titánico, pero también sin duda es indispensable realizarlo si lo que se desea es comprender la dinámica social de la pandemia y mejorar las estrategias de prevención y control con las que abordar eficazmente futuras emergencias sanitarias de esta envergadura.

\section{Referencias}

1. AfP/EFE (2021, 5 de febrero). Los expertos de la oms en Wuhan descartan la teoría de la fuga del virus de un laboratorio. El Mundo. https://www.elmundo.es/ciencia-y-salud/salud/2021/02/05/601cf2b921efa0bd1b8b45d7.html.

2. Aibar, E. (2002). Controversias tecnocientíficas públicas: La pericia no es siempre suficiente. Digitum, (4).

3. Alcíbar, M. (2007). Comunicar la ciencia: La clonación como debate periodístico. Consejo Superior de Investigaciones Científicas.

4. Alsedo, Q. (2020, 19 de abril). 2.200 camas ucı estuvieron libres en España mientras 12.000 ancianos morían sin asistencia en las residencias. El Mundo. https://www.elmundo.es/ciencia-y-salud/salud/2020/04/19/5e9b579521efa084288b45de.html

5. Amat, F., Falcó-Gimeno, A., Arenas, A., \& Muñoz, J. (2020, 6 de abril). Pandemics meet democracy: Experimental evidence from the covid-19 crisis in Spain. SocArXiv. https://doi.org/10.31235/osf.io/dkusw

6. Andersen, K. G., Rambaut, A., Lipkin, W. I., Holmes, E. C. \& Garry, R. F. (2020). The proximal origin of SARS-CoV-2. Nature Medicine, (26), 450-452.

7. Beck, U. (1992). Risk society: Towards a new modernity. Sage.

8. Boni, M. F., Lemey, P., Jiang, X., Tsan-Yuk Lam, T., Perry, B. W., Castoe, T. A., Rambaut, A., \& Robertson, D. L. (2020). Evolutionary origins of the SARS-CoV-2 sarbecovirus lineage responsible for the covid-19 pandemic. Nature Microbiology, (5), 1408-1417.

9. Caro, G. (2020, 1 de abril). Moncloa recula tras el manifiesto y se abre a un sistema de ruedas de prensa alternativo. ABc. https://www.abc.es/espana/abci-moncloa-ignora-manifiesto-periodistas-contra-sistema-ruedas-prensa-202004011445_noticia.html 


\section{DISERTACIONES}

ENSAYOS

Comunicación y controversias sociocientificas en salud y medio ambiente

ISSN: $1856-9536$

Doi: https://doi.org/10.12804/revistas.urosario.edu.co/disertaciones/a.10334

Volumen 14, Número 2 / Julio-diciembre 2021

Versión PDF para imprimir desde

http://revistas.urosario.edu.co/index.php/disertaciones

10. Castillo-Esparcia, A., Fernández-Souto, A-B., \& Puentes-Rivera, I. (2020). Comunicación política y covid-19: Estrategias del Gobierno de España. Profesional de la Información, 29(4), e290419.

11. Cheshire, T. (2021, 3 de febrero). covid-19: who team in Wuhan sees data 'no one has seen before' - and does not rule out coronavirus escaped from a lab. Sky News. https://news.sky.com/story/covid-19-whoteam-in-wuhan-sees-data-no-one-has-seen-before-and-does-not-rule-out-coronavirus-escaped-from-alab-12206781

12. Centro de Investigaciones Sociológicas. (2020). Barómetro del cls de octubre 2020. http://datos.cis.es/pdf/ Es3296marmt_A.pdf

13. Coronavirus Resource Center. (2021, 31 de enero). Mortality in the most affected countries. Johns Hopkins University \& Medicine. https://coronavirus.jhu.edu/data/mortality

14. Cortes Generales. (2020). Diario de sesiones del Congreso de los Diputados del 10 de junio de 2020. https:// www.congreso.es/public_oficiales/L14/CONG/DS/PL/DSCD-14-PL-27.PDF

15. European Centre for Disease Prevention and Control (ECDC). (2020a). Rapid risk assessment: Outbreak of novel coronavirus disease 2019 (covid-19): Increased transmission globally. https://www.ecdc.europa. eu/sites/default/files/documents/RRA-outbreak-novel-coronavirus-disease-2019-increase-transmission-globally-covid-19.pdf

16. European Centre for Disease Prevention and Control (ECDC). (2020b). Threat assessment brief: Pneumonia cases possibly associated with a novel coronavirus in Wuhan, China. https://www.ecdc.europa.eu/sites/ default/files/documents/Threat-assessment-Pneumonia-cases-possibly-associated-to-a-novel-coronavirus-in-Wuhan-China.pdf

17. Echeverría, J. (2003). La revolución tecnocientífica. Fondo de Cultura Económica.

18. covid-19 in Spain: A predictable storm? [Editorial]. (2020). The Lancet, 5(11), e568. https://doi.org/10.1016/ S2468-2667(20)30239-5

19. EFE. (2021, 2 de febrero). El PSOE advierte a Ayuso: 'La salud debe estar por encima de la economía'. elDiario. es. https://www.eldiario.es/sociedad/psoe-advierte-ayuso-salud-debe-economia_1_7186845.html

20. Engelhardt, H. T., \& Caplan, A. L. (Eds.). (1987). Scientific controversies: Case studies in the resolution and closure of disputes in science and technology. Cambridge University Press.

21. Europa Press. (2020a, 26 de mayo). China se opone a la 'politización' del origen del coronavirus y pide centrarse en 'la ciencia y los hechos'. https://www.europapress.es/internacional/noticia-china-opone-politizacion-origen-coronavirus-pide-centrarse-ciencia-hechos-20200526173221.html

22. Europa Press. (2020b, 26 de octubre). pp plantea 'equilibrar salud y economía' con apoyo a comercio, hostelería y venta ambulante. La Vanguardia. https://www.lavanguardia.com/local/sevilla/20201026/4921561790/ pp-plantea-equilibrar-salud-y-economia-con-apoyo-a-comercio-hosteleria-y-venta-ambulante.html

23. Fita, J., \& Villalonga, C. (2021, 20 de febrero). Confinar siete días antes habría salvado más de 20.000 vidas en la primera ola en España. La Vanguardia. https://www.lavanguardia.com/vida/20210220/6256260/ coronavirus-cientificos-senalan-habrian-salvado-vidas-confinado-7-dias-antes-primera-ola.html

24. Fullman, N. et al. (2018). Measuring performance on the Healthcare Access and Quality Index for 195 countries and territories and selected subnational locations: a systematic analysis from the Global Burden of Disease Study 2016. The Lancet, 391(10136), 2236-71. https://doi.org/10.1016/S0140-6736(18)30994-2 


\section{DISERTACIONES}

ENSAYOS

Comunicación y controversias sociocientificas en salud y medio ambiente

ISSN: $1856-9536$

Doi: https://doi.org/10.12804/revistas.urosario.edu.co/disertaciones/a.10334

Volumen 14, Número 2 / Julio-diciembre 2021

Versión PDF para imprimir desde

http://revistas.urosario.edu.co/index.php/disertaciones

25. Gómez, J. A. (2021, 9 de febrero). El epidemiólogo español que triunfa en Harvard: "Diciembre era un momento para la cautela”. El Español. https://www.elespanol.com/ciencia/20210209/miguel-hernan-cargos-civiles-militares-prioridad-vacuna/557444892_0.html

26. García-Basteiro, A. et al. (2020). The need for an independent evaluation of the coviD-19 response in Spain. The Lancet, 396(10250), 529-530. https://doi.org/10.1016/S0140-6736(20)31713-X

27. Graham, S. S., \& Walsh, L. (2019). There's no such thing as a scientific controversy. Technical Communication Quarterly, 28(3), 192-206.

28. Guindo, D. (2020, 28 de diciembre). Buscar el equilibrio entre salud y economía es poco científico. Las Provincias. https://www.lasprovincias.es/comunitat/buscar-equilibrio-salud-20201226202423-nt.html? ref=https: \%2F\%2Fwww.google.com \%2F

29. Horizonte. (2921, 7 de enero). Informe Covid. Telecinco.

30. Juste Ballesta, J., Figueras Huerta, A., \& Echeverría Mayo, J. E. (2020, 21 de mayo). Los murciélagos, las otras víctimas del SARS-CoV-2. The Conversation. https://theconversation.com/los-murcielagos-las-otrasvictimas-del-SARS-cov-2-138870

31. Maqueda, A. (2020, 23 de septiembre). La economía española cayó un 17,8\% en el segundo trimestre, la mayor caída en tiempos de paz. El País. https://elpais.com/economia/2020-09-23/la-economia-espanolacayo-un-178-en-el-segundo-trimestre-algo-menos-de-lo-estimado.html

32. Martín Plaza, A. (2021, 20 de enero). Una tercera ola de récord: La factura dos semanas después de celebrar la Navidad sin doblegar la curva. RTVE. https://www.rtve.es/noticias/20210120/efecto-navidad-tercera-ola/2067660.shtml

33. Mateo, J. J. (2021, 1 de febrero). Los barones del pp no respaldan la apuesta de Díaz Ayuso por mantener la hostelería abierta. El País. https://elpais.com/espana/madrid/2021-02-01/los-barones-del-pp-no-respaldan-la-apuesta-de-diaz-ayuso-por-mantener-la-hosteleria-abierta.html

34. Miller, D. S. (2016). Public trust in the aftermath of natural and na-technological disasters: Hurricane Katrina and the Fukushima Daiichi nuclear incident. International Journal of Sociology and Social Policy, 36(5/6), 410-431.

35. Ministerio de Sanidad de España. (2020a, 10 de junio). Actualización 132: Enfermedad por el coronavirus (covid-19). https://www.mscbs.gob.es/profesionales/saludPublica/ccayes/alertasActual/nCov/documentos/Actualizacion_132_covid-19.pdf.

36. Ministerio de Sanidad de España. (2020b, 23 de julio). Actualización 169: Enfermedad por el coronavirus (covid-19). https://www.mscbs.gob.es/profesionales/saludPublica/ccayes/alertasActual/nCov-China/ documentos/Actualizacion_169_covid-19.pdf

37. Ministerio de Sanidad de España. (2021, 5 de febrero). Actualización 306: Enfermedad por el coronavirus (covid-19). https://www.mscbs.gob.es/profesionales/saludPublica/ccayes/alertasActual/nCov/documentos/Actualizacion_306_covid-19.pdf

38. Organización Mundial de la Salud (oms). (2020, 21 de diciembre). Cepa variante del SARS-CoV-2: Reino Unido. https://www.who.int/csr/don/21-december-2020-SARS-cov2-variant-united-kingdom/es/ 


\section{DISERTACIONES}

ENSAYOS

Comunicación y controversias sociocientificas en salud y medio ambiente

ISSN: 1856-9536

Doi: https://doi.org/10.12804/revistas.urosario.edu.co/disertaciones/a.10334

Volumen 14, Número 2 / Julio-diciembre 2021

Versión PDF para imprimir desde

http://revistas.urosario.edu.co/index.php/disertaciones

39. Orea, L., \& Álvarez, I. C. (2020). How effective has the Spanish lockdown been to battle covid-19?: A spatial analysis of the coronavirus propagation across provinces. Fundación de Estudios de Economía Aplicada. https://documentos.fedea.net/pubs/dt/2020/dt2020-03.pdf

40. Piña, R. (2020, 6 de abril). Moncloa se ve obligada a rectificar y permitirá que los periodistas pregunten en directo por videoconferencia. El Mundo. https://www.elmundo.es/espana/2020/04/05/5e8a1a99fc6c8372508b45d3.html.

41. Ramírez, A. (2020, 28 de octubre). ¿Dejar de llamarlo 'toque de queda'? 'Es una manipulación del lenguaje’. El Confidencial. https://www.elconfidencial.com/cultura/2020-10-28/sanchez-toque-de-queda-lenguajerae-eufemismo_2808112/

42. Rodríguez-Morales, A. J., Bonilla-Aldana, D. K., Balbin-Ramón, G. J., Rabaan, A. A., Paniz-Mondolfi, A., Pagliano, P., \& Esposito, S. (2020). History is repeating itself: Probable zoonotic spillover as the cause of the 2019 novel coronavirus epidemic. Le Infezioni in Medicina, (1), 3-5. https://www.acin.org/images/ guias/coronavirus/2_infez_med_1_2020_01_Rodriguez_003-005-2019nCoV-FINAL.pdf

43. Sánchez, P. (2020, 25 de octubre). Intervención de Pedro Sánchez. Presidencia de Gobierno. https://www. lamoncloa.gob.es/consejodeministros/Paginas/EnlaceTranscripciones2020/251020-presidente.aspx

44. Socialistas Vascos. (2020, 5 de julio). 12J | Idoia Menida y Pedro Sánchez en \#Bilbao \#IdoiaLehendakari \#Votaldoia \#VotaPSE [Video]. YouTube. https://www.youtube.com/watch?v=VKJQeS1_uCk

45. Soto, A. (2020, 8 de noviembre). Una desescalada demasiado rápida que precipitó la segunda ola. La Voz de Galicia. https:/www.lavozdegalicia.es/noticia/sociedad/2020/11/07/desescalada-rapida-precipito-segunda-ola/00031604778493739709394.htm

46. Stegmann, J. G. (2021, 13 de enero). Simón se vuelve a equivocar: La cepa británica aumenta un 70 por ciento los contagios. ABc. https://www.abc.es/sociedad/abci-simon-vuelve-equivocar-cepa-britanica-aumenta-70-ciento-contagios-202101122249_noticia.html

47. Stewart, C. O. (2009). Socioscientific Controversies: A Theoretical and Methodological Framework. Communication Theory, 19, 124-145.

48. Trias-Llimós, S., Alustiza, A., Prats, C., Tobias, A., \& Riffe, T. (2020). The need for detailed covid-19 data in Spain. The Lancet, 5(11), e576. https://doi.org/10.1016/S2468-2667(20)30234-6

49. Lam, T. T. et al. (2020). Identifying SARS-CoV-2-related coronaviruses in Malayan pangolins. Nature, 583(7815), 282-285. https://doi.org/10.1038/s41586-020-2169-0

50. Velarde, G. (2020, 28 de diciembre). El $99 \%$ de las 68.000 empresas destruidas en España por la pandemia tiene menos de 50 trabajadores. elEconomista.es. https://www.eleconomista.es/economia/ noticias/10961067/12/20/El-99-de-las-68000-empresas-destruidas-en-Espana-por-la-pandemia-tienemenos-de-50-trabajadores.html

51. Vidal Liy, M. (2021a, 11 de enero). China da luz verde al viaje de la misión de la oms para investigar el origen de la pandemia. El País. https://elpais.com/sociedad/2021-01-11/china-da-luz-verde-al-viaje-de-la-mision-de-la-oms-para-investigar-el-origen-de-la-pandemia.html

52. Vidal Liy, M. (2021b, 9 de febrero). La oms concluye que el virus es de origen animal y sugiere que no empezó en el mercado de Wuhan. El País. https://elpais.com/sociedad/2021-02-09/la-oms-concluye-que-el-virusprocede-de-un-animal-y-sugiere-que-no-se-origino-en-el-mercado-de-wuhan.html 


\section{DISERTACIONES}

ENSAYOS

53. Villaécija, R. (2020, 14 de mayo). Piden la dimisión de Garzón por decir que el turismo español es "precario, estacional y con bajo valor añadido". El Mundo. https://www.elmundo.es/economia/macroeconomia/2020/05/14/5ebd6bf321efa0ce108b45aa.html

54. World Economic Forum. (2019). The Global Competitiveness Report 2019. http://www3.weforum.org/docs/ WEF_TheGlobalCompetitivenessReport2019.pdf

55. Worldometer. (2020, 25 de abril). covid-19 Coronavirus pandemic. https://www.worldometers.info/ coronavirus/

56. Yuan, S., Jiang, S.-C., \& Li, Z.-L. (2020). Analysis of possible intermediate hosts of the new coronavirus SARS-CoV-2. Frontiers in Veterinary Science, 7, 379. https://doi.org/10.3389/fvets.2020.00379 